\title{
Feline immunodeficiency virus vectors persistently transduce nondividing airway epithelia and correct the cystic fibrosis defect
}

\author{
Guoshun Wang, ${ }^{1}$ Vladimir Slepushkin, ${ }^{2}$ Joseph Zabner, ${ }^{2}$ Shaf Keshavjee, ${ }^{3}$ Julie C. Johnston, ${ }^{4}$ \\ Sybille L. Sauter, ${ }^{4}$ Doug J. Jolly, ${ }^{4}$ Thomas W. Dubensky, Jr., ${ }^{4}$ Beverly L. Davidson, ${ }^{2}$ \\ and Paul B. McCray, Jr. ${ }^{1}$
}

\author{
${ }^{1}$ Program in Gene Therapy, Department of Pediatrics, and \\ ${ }^{2}$ Department of Internal Medicine, University of Iowa College of Medicine, Iowa City, Iowa 52242, USA \\ ${ }^{3}$ Toronto Lung Transplant Program, University of Toronto, Toronto, Ontario M5G 2C4, Canada \\ ${ }^{4}$ Chiron Technologies, Center for Gene Therapy, San Diego, California 92121, USA
}

Address correspondence to: Paul B. McCray, Jr., Department of Pediatrics, University of Iowa College of Medicine, 200 Hawkins Drive Iowa City, Iowa 52242, USA.

Phone: (319) 356-4866; Fax: (319) 356-7171; E-mail: paul-mccray@uiowa.edu.

Received for publication September 10, 1999, and accepted in revised form October 22, 1999.

Several problems limit the application of gene transfer to correct the cystic fibrosis (CF) $\mathrm{Cl}^{-}$transport defect in airway epithelia. These include inefficient transduction with vectors applied to the apical surface, a low rate of division by airway epithelial cells, failure of transgene expression to persist, and immune responses to vectors or vector-encoded proteins. To address these issues, we used a feline immunodeficiency virus-based (FIV-based) vector. FIV vector formulated with a calcium chelator transduced fully differentiated, nondividing human airway epithelia when applied to the apical surface. FIV-based vector encoding the cystic fibrosis transmembrane conductance regulator cDNA corrected the $\mathrm{Cl}^{-}$transport defect in differentiated CF airway epithelia for the life of the culture (>3 months). When this approach was applied in vivo, FIV vector expressing $\beta$-galactosidase transduced $1-14 \%$ of adult rabbit airway epithelia. Transduced cells were present in the conducting airways, bronchioles, and alveoli. Importantly, gene expression persisted, and cells with progenitor capacity were targeted. FIV-based lentiviral vectors may be useful for the treatment of genetic lung diseases such as $\mathrm{CF}$.

This article may have been published online in advance of the print edition. The date of publication is available from the JCI website, http://www.jci.org. J. Clin. Invest. 104:R55-R62 (1999).

\section{Introduction}

Gene therapy is the most direct means to correct the $\mathrm{Cl}^{-}$transport defect responsible for cystic fibrosis $(\mathrm{CF})$ lung disease (1-4). However, several problems limit the successful in vivo application of gene transfer to airway epithelia. These include inefficient transduction, immune responses to vectors and vector-encoded proteins, and lack of persistent transgene expression. Such limitations must be overcome if gene transfer is to advance as a treatment for $\mathrm{CF}$ and other lung diseases.

Recombinant adeno-associated virus (AAV) $(5,6)$, Moloney murine leukemia virus (MuLV) (7-11), and lentivirus (12) vectors address the problem of poor persistence due to their ability to integrate. Lentivirusbased vectors offer the advantage of infecting nondividing cells, a significant consideration in the airways where most cells are mitotically inactive (12). However, limited studies to date suggest that HIV-based lentivirus vectors inefficiently transduce differentiated airway epithelia (13).

A first-generation lentivirus vector derived from the feline immunodeficiency virus (FIV) was recently reported (14). Similar to HIV, FIV vectors transduce nondividing cells $(14,15)$. Wild-type FIV is antigenically and genetically distinct from HIV and does not infect human cells or cause disease in humans (16). Therefore, FIV-based vectors may offer addition- al safety features compared with HIVbased systems (15). We developed a second-generation FIV vector in which unnecessary trans-acting elements (vif, $\operatorname{orf2}$ ) were deleted, further reducing the possibility of production of replication competent virus (15). Here, we use this FIV-based vector to efficiently transduce airway epithelia in vitro and in vivo. We present novel methods of vector formulation and delivery that facilitate gene transfer to the airways in vivo. FIV vectors may offer advantages over other vectors for airway gene transfer.

\section{Methods}

Culture of buman airway epithelia. Airway epithelia were isolated from nasal polyps, trachea, and bronchi and grown at the air-liquid interface as described previously (17). All preparations used were well differentiated $(>2$ weeks old; resistance $>1,000 \mathrm{ohm} \times$ $\left.\mathrm{cm}^{2}\right)(17,18)$. This study was approved by the Institutional Review Board at the University of Iowa.

Drugs and chemicals. Aphidicolin (20 $\mu \mathrm{g} / \mathrm{mL}$ ) (Sigma Chemical Co., St. Louis, Missouri, USA) was applied to cells for 24 hours before retroviral transduction to arrest cell growth in G1/S phase $(12,14)$. To inhibit retroviral RT, $5 \mu \mathrm{M} 3$ '-azido-3'-deoxythymidine (AZT; Glaxo Wellcome, Research Triangle Park, North Carolina, USA) was added at the time of viral transduction.

Vector production. The second-generation FIV vector system was reported previously (15). Plasmid constructs 
consist of an FIV packaging construct with a deletion in the env gene and mutations in vif and orf2, an FIV vector construct expressing either cytoplasmic Escherichia coli $\beta$-galactosidase or cystic fibrosis transmembrane conductance regulator (CFTR) genes, and an envelope plasmid in which the human cytomegalovirus (CMV) early gene promoter directs transcription of the vesicular stomatitis virus $\mathrm{G}$ protein (VSV-G). In the vector constructs, the CMV promoter directs $\beta$-galactosidase expression (FIV- $\beta$ gal), whereas the MuLV long terminal repeat promoter directs CFTR expression (FIV-CFTR) (19).

VSV-G-pseudotyped FIV vector particles were generated by transient transfection of plasmid DNA into 293T cells as described previously (15). Each FIV- $\beta$ gal preparation was titered on NIH 3 T3 cells by limiting dilutions; final titers of approximately $5 \times 10^{7}$ to $5 \times 10^{9} \mathrm{CFU} / \mathrm{mL}$ were obtained. To titer the FIV-CFTR vector, a PCRbased assay system was developed. HT1080 target cells were transduced with serial dilutions of crude or processed FIV vector preparations in the presence of $4 \mu \mathrm{g} / \mathrm{mL}$ hexadimethrine bromide (Sigma Chemical Co.). Twentyfour hours later, media were changed and cells were cultured for an additional 24-48 hours. The samples were washed with $1 \mathrm{X}$ PBS, and incubated with $2.5 \mathrm{~mL}$ of lysis buffer $(100 \mathrm{mM}$ Tris [pH 8], $5 \mathrm{mM}$ EDTA, 0.2\% SDS, $100 \mathrm{mM} \mathrm{NaCl}$, and $100 \mu \mathrm{g} / \mathrm{mL}$ pro- teinase K [QIAGEN Inc., Valencia, California, USA]) at $37^{\circ} \mathrm{C}$ for 2 hours, and the DNA was precipitated. DNA pellets were washed with $70 \%$ ethanol and resuspended in $500 \mu \mathrm{L}$ TE buffer, and total genomic DNA was quantified by staining with Hoechst dye H33258 and compared directly against calf thymus DNA standards using the CytoFluor II fluorometer (PerSeptive Biosystems, Framingham, Massachusetts, USA). A total of $100 \mathrm{ng}$ of each genomic DNA sample was subjected to automated PCR (50 $\mu \mathrm{L}$ volume) using a PE ABI Prism 7700 system (Perkin-Elmer Corp., Norwalk, Connecticut, USA) and a synthetic oligonucleotide primer set directed against FIV packaging signal sequences, yielding an 80-bp product. The resulting fluorescence was detected, and provector copy number titer was expressed as transduction units per milliliter $(\mathrm{TU} / \mathrm{mL})$. Titers of $9.7 \times 10^{8}$ to $4.6 \times 10^{9} \mathrm{TU} / \mathrm{mL}$ were obtained in 2 preparations.

\section{Gene transfer}

In vitro. To transduce differentiated human epithelia, the FIV vector was mixed with cell culture medium to a final volume of $100 \mu \mathrm{L}$ ( 10 moi). This mixture was applied to either the apical surface or the basal surface as described previously (9). To enhance transduction from the apical surface, vector was mixed at a $1: 1(\mathrm{vol} / \mathrm{vol})$ ratio with 12 mM EGTA HEPES/saline solution ( $\mathrm{pH}$ 7.3) and applied apically for 4 hours as reported previously for $\mathrm{MuLV}$ vectors (9). Polybrene $(8 \mu \mathrm{g} / \mathrm{mL})$ was included in the transduction solutions.

To study the persistence of recombinant FIV-mediated correction of CFTR $\mathrm{Cl}^{-}$current, results were compared with recombinant adenovirus. We previously reported that adenovirus infects human airway epithelia through the basolateral side by a fiber-dependent mechanism (20). Ad2/CFTR-16 (50 moi) (21) was applied in a $25-\mu \mathrm{L}$ volume to the bottom of the epithelia. After 30 minutes, the epithelia were rinsed and returned to the culture dish. Epithelia were studied at intervals for the life of the culture (90-180 days).

A control experiment was performed to rule out protein transfer or pseudotransduction as reported for concentrated AAV and retroviral vectors (22, $23)$. When applying the FIV- $\beta$ gal vector/EGTA solution to the apical surface, cells were treated with AZT to inhibit the retroviral RT. AZT-treated cells showed no significant expression of vector-encoded product (not shown), confirming that FIV-vector transduction under these experimental conditions was not due to protein transfer. In vivo. For tracheal gene transfer, adult New Zealand white rabbits were anesthetized with $32 \mathrm{mg} / \mathrm{kg}$ ketamine, $5.1 \mathrm{mg} / \mathrm{kg}$ xylazine, and $0.8 \mathrm{mg} / \mathrm{kg}$ acepromazine intramuscularly; a ventral midline incision was made; and a tracheotomy was performed. An approximately $1.5-\mathrm{cm}$ tracheal segment cepha-

\section{Figure 1}

FIV vectors transduce nondividing airway epithelia in vitro. (a) Application of FIV- $\beta$ gal (moi 10) to the apical surface of the epithelial sheet resulted in no gene transfer. Representative en face view of X-gal stained epithelia 3 days after vector application. (b) FIV- $\beta$ gal vector applied to airway epithelia from the basolateral surface in vitro (moi 10) resulted in gene transfer. Representative en face view is shown. (c) Gene transfer from the apical surface with VSV-G FIV is enhanced by physical disruption of epithelia. The epithelial sheet was scratched with a pipette tip prior to apical vector application. En face view shows gene transfer (gray cells) only along the area of epithelial disruption. (d) FIV transduces aphidicolin growth-arrested cells (en face view). Vector was applied to apical surface in the presence of $6 \mathrm{mM}$ EGTA in hypotonic buffer. Approximately $17 \%$ of epithelia were transgene positive (range $12-22 \% ; n=5$ epithelia from 2 different preparations). For cells in control media without aphidicolin, approximately $20 \%$ of cells expressed the transgene (data not shown; range $8-30 \%$; $n$ $=5$ epithelia from 3 different preparations). (e) Quantification of gene transfer results under conditions shown in $\mathrm{d}$ (mean $\pm \mathrm{SEM} ; n=5$ epithelia; 3 different preparations).
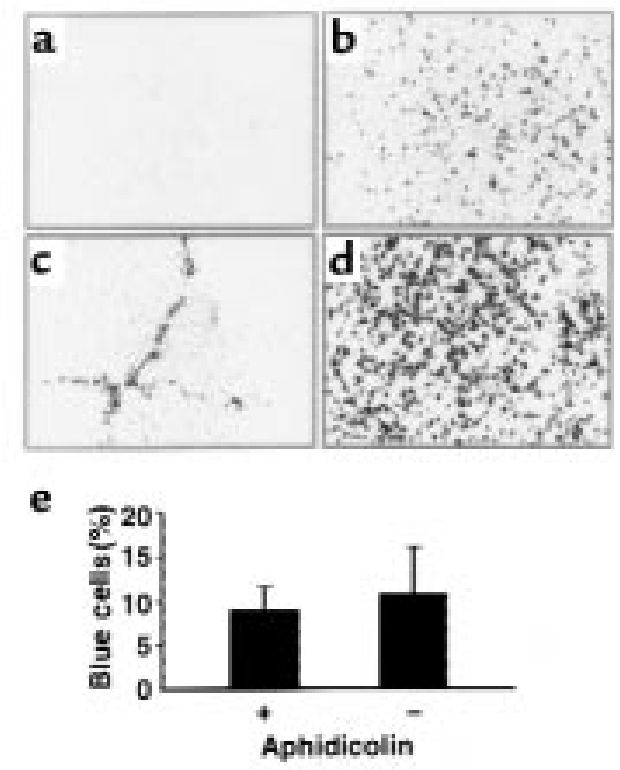

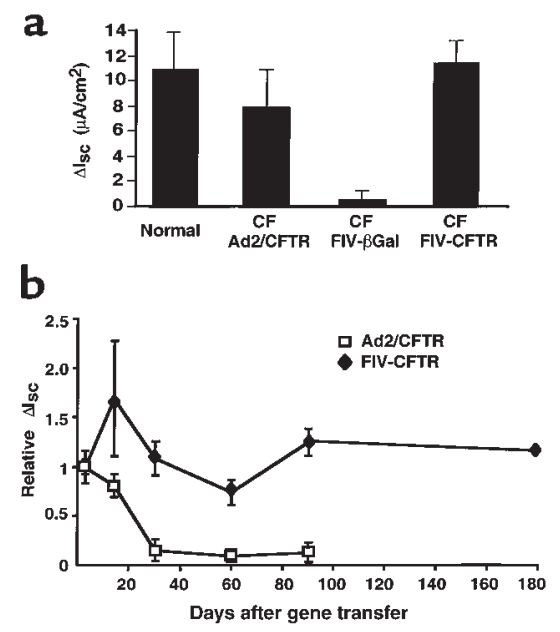

lad to the tracheotomy was isolated and cannulated on each end with PE 330 tubing (Becton Dickinson, Parsippany, New Jersey, USA). The tracheal segment was rinsed and then filled with a solution of $12 \mathrm{mM}$ EGTA in $10 \mathrm{mM}$ HEPES buffer ( $\mathrm{pH} 7.4$, "hypotonic buffer") for 30-60 minutes. The EGTA solution was then replaced with $300 \mu \mathrm{L}$ of FIV- $\beta$ gal vector (titer $1 \times 10^{8}$ to $5 \times 10^{8}$ $\mathrm{CFU} / \mathrm{mL}$ ). The vector solution was left in place for 45 minutes, and then the cannulae were removed and the incisions closed. Five days or 6 weeks later, the tissues studied for $\beta$-galactosidase expression. For lower airway gene transfer, a PE50 catheter passed via the trachea until it lodged in a subsegmental bronchus. A total of 200-600 $\mu \mathrm{L}$ of FIVBgal formulated in hypotonic buffer with $6 \mathrm{~mm}$ EGTA was instilled. Five days later, the tissues were studied for $\beta$ galactosidase expression.

Tissue histochemistry

$\beta$-galactosidase expression. Epithelial cells were fixed and $\mathrm{X}$-gal stained as reported elsewhere $(9,24)$. Epithelia counterstained with DAPI were examined microscopically en face for $\beta$-galactosidase expression. The percentage of $\beta$-galactosidase-positive cells was determined by counting a minimum of 1,000 cells from representative en face views of each treated epithelia.

Rabbit tissues were fixed in $2 \%$ paraformaldehyde/PBS overnight, X-gal stained, and embedded in paraffin, and sections were cut for histological examination (24). Sections were counterstained with nuclear fast red or hematoxylin and eosin. To determine the

\section{Figure 2}

FIV-CFTR corrects the $\mathrm{CF} \mathrm{Cl}^{-}$transport defect. CF epithelia were transduced from the apical surface in the presence of EGTA with 10 moi of FIV vector expressing either $\beta$-galactosidase or human CFTR. For comparison, another group of CF cells received Ad2/CFTR (moi 50, basolateral application). At time points of 3, 13, 30, 60, 90, and 180 days later, epithelia were mounted in Ussing chambers, and the change in short circuit current was measured in

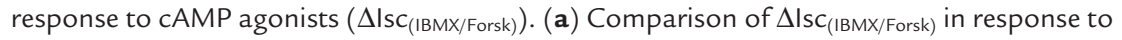
cAMP agonists in CF epithelia transduced with adenovirus or FIV vectors, 3 days after gene transfer. Both Ad- and FIV-transduced epithelia express CAMP-activated $\mathrm{Cl}^{-}$currents similar to normal cells ( $n=5$ CF epithelia; $n=5$ normal epithelia, for each time point). (b) CFTR expression persists in FIV-transduced epithelia. CF epithelia were transduced with FIV- $\beta$ gal, FIV-CFTR, or Ad2/CFTR and $\Delta \mathrm{Isc}_{(\mathrm{IBMX} / \text { Forsk })}$ measured at the indicated time points after gene transfer ( $n=5$ CF epithelia; $n=5$ normal epithelia, for each time point). Data from each experiment were normalized to the mean IsC $_{(B B M X / F o r s k)}$ seen 3 days after infection. One CF preparation was viable 6 months after gene transfer.

percentage of $\beta$-galactosidase-expressing cells in each 1.5 - to 2 -cm tracheal specimen, serial sections were cut every $20 \mu \mathrm{m}$, and $\geq 50$ slides were examined. To quantify gene transfer to lower airways, the blue tissue areas of the Xgal-stained lungs (see Figure 4a) were dissected and embedded in paraffin, and serial sections cut at $40-\mu \mathrm{m}$ intervals. The percentage of $\beta$-galactosidase-positive cells in lower airway tissues was quantified by cell counting. $\beta$-galactosidase-expressing cells were categorized by the size of the airway in which expression was noted (>750 $\mu \mathrm{m}, 500-750 \mu \mathrm{m}, 250-500 \mu \mathrm{m}, 0-250$ $\mu \mathrm{m})$ using a calibrated eyepiece reticle. To identify the cell types expressing $\beta$ galactosidase, standard morphologic criteria were used. Transgene-expressing cells were identified by their physical characteristics: (a) ciliated cells are columnar cells with cilia; (b) goblet cells are columnar cells containing secretory granules; (c) basal cells are basally located cuboidal cells having no contact with the mucosal surface; (d) intermediate cells are columnar cells in the lower half of the epithelium having no contact with the lumen; (e) Clara cells are nonciliated, columnar to cuboidal surface cells that are more prevalent in the distal airways; and (f) alveolar type II cells are cuboidal, "corner" cells of the alveolar epithelium.

Measurement of transepithelial CFTR $\mathrm{Cl}^{-}$ current. To measure transepithelial bioelectric properties, epithelia were mounted in Ussing chambers and studied 3, 13, 30, 60, 90, and 180 days after gene transfer as described previously (17). The cAMP-stimulated Isc
$\left(\operatorname{Isc}_{(\mathrm{IBMX} / \mathrm{Forsk})}\right)$ is the increase in current after basolateral addition of cAMP agonists $(10 \mu \mathrm{M}$ forskolin plus $100 \mu \mathrm{M} 3$ isobutyl 1-methylxanthine [IBMX]) in the presence of $10 \mu \mathrm{M}$ amiloride. Data from each experiment were normalized to the mean Isc(IBMX/Forsk) seen 3 days after transduction. CF airway epithelia were genotyped and were compound heterozygotes for the $\Delta \mathrm{F} 508$ mutation $(\Delta \mathrm{F} 508 /-, \Delta \mathrm{F} 508 / 1717-1 \mathrm{G} \rightarrow \mathrm{A})$.

\section{Results}

FIV vectors transduce nondividing airway epithelia in vitro. On the basis of previous literature $(25,26)$ as well as our own studies with MuLV $(9,11)$, we suspected that the receptors for VSVG-pseudotyped FIV vectors were only expressed on the basolateral surface of airway epithelia. Indeed, when VSVG-pseudotyped FIV- $\beta$ gal was applied to the apical surface, no gene transfer occurred (Figure 1a). In contrast, FIV$\beta$ gal applied to the basolateral surface transduced the epithelia (Figure 1b). We hypothesized that if epithelial junctions were opened, FIV vector particles would have a better chance to interact with cell-surface receptors and gain entry when applied apically. Scratching the epithelial sheet with a pipette tip before applying vector to the apical surface enhanced gene transfer only in areas where the cells were mechanically disrupted (Figure 1c). Thus, if receptors were made accessible, gene transfer was achieved with VSV-G-pseudotyped FIV vectors.

To demonstrate that FIV vectors transduce nondividing epithelia, we performed experiments in the pres- 
ence or absence of aphidicolininduced growth arrest $(12,14)$. As we found previously that calcium chelation with EGTA and hypotonic solutions disrupted epithelial junctions and facilitated gene transfer with apically applied MuLV vectors (9), a similar approach was used with the FIV vector. Formulation of FIV- $\beta$ gal with 6 mM EGTA in a hypotonic buffer $(\sim 10$ moi) greatly increased gene transfer from the apical surface (Figure 1d). Approximately $17 \%$ of epithelia growth-arrested with aphidicolin were transgene positive 3 days after transduction, whereas approximately $20 \%$ of epithelia in control media were transduced (Figure 1, d and e). Previous studies showed that approximately $7 \%$ of cells are proliferating in this model as assayed by BrdU histochemistry (9). The EGTA solution alone had no effect on cell proliferation as assayed by BrdU histochemistry (data not shown). Thus, when allowed access to receptors, FIV vectors effectively transduced nondividing epithelia.

FIV vectors coding for CFTR persistently correct the $\mathrm{CF} \mathrm{Cl}^{-}$transport defect. On the basis of the results in normal human airway epithelia, we hypothesized that recombinant FIV vectors expressing CFTR would complement the $\mathrm{Cl}^{-}$ transport defect in well-differentiated CF epithelia. For these studies, we used primary organotypic cultures of human airway epithelia from patients with $\mathrm{CF}$, for the following reasons. Primary cultures of differentiated human CF airway epithelia recapitulate several important aspects of in vivo airway epithelial biology and CF disease. Cells cultured in this fashion morphologically resemble the human airways in vivo $(17,18)$. Similar to the in vivo human airways, they are relatively resistant to transduction by both viral and nonviral vectors applied to the apical surface $(9,17,27,28)$. They manifest the electrolyte and liquid transport defects characteristic of CF $(18,29)$. Importantly, unlike the long-term survival and minimal evidence of lung disease reported for CFTR-null mice or mice with specific human CFTR mutations (30-35), cultured human CF epithelia show an increased susceptibility to bacterial infection (36).

Tracheal epithelia were transduced in vitro from the apical surface with FIV-CFTR. Correction of the CFTR $\mathrm{Cl}^{-}$transport defect was assayed by measuring the change in short-circuit current in response to cAMP agonists $\left(\Delta \operatorname{Isc}_{(\text {IBMX/Forsk) }}\right)$, from 3 days to 6 months after gene transfer (Figure 2). CF epithelia transduced with FIVCFTR or adenovirus expressing CFTR uniformly demonstrated $\mathrm{Cl}^{-}$secretion in response to cAMP agonists, whereas control cells treated with FIV- $\beta$ gal showed no response (Figure $2 \mathrm{a}$ ). The $\mathrm{Cl}^{-}$secretory responses in the corrected cells (Figure 2, a and b) were similar to those measured in normal airway epithelia (Figure 2, a and b). In cells transduced with adenovirus, $\Delta \operatorname{Isc}_{\text {(IBMX/Forsk) }}$ gradually declined over time. In contrast, the net
$\Delta \mathrm{Isc}_{(\mathrm{IBMX} / \mathrm{Forsk})}$ in FIV transduced cells remained stable (Figure $2 b$ ). In 1 FIVCFTR-transduced culture that remained viable for 6 months, cAMPactivated $\mathrm{Cl}^{-}$current persisted at similar levels as day 3 (Figure 2b).

FIV vectors transduce airway epithelia in vivo. FIV vectors might also effectively transduce airway epithelia in vivo if VSV-G receptors were accessible. We used a similar protocol of epithelial junction disruption to test FIV vectors in vivo. After EGTA pretreatment, FIV$\beta$ gal vector was applied to the luminal surface of the trachea in adult rabbits. Five days later, the tissues were removed and studied for $\beta$-galactosidase expression. As shown in Figure 3, a-e, cells throughout the epithelium expressed the transgene. The transduction efficiency was $4.8 \pm 5.6 \%$ (mean \pm SEM; range: $1-14 \% ; n=4$ ). The treated epithelia appeared intact, without evidence of injury or inflammatory cell infiltrates. Of note, basal cells, intermediate cells, and both ciliated and nonciliated surface cells expressed $\beta$-galactosidase (Figure 3, $\mathrm{b}-\mathrm{e})$. Previous studies in several species showed that the mitotic labeling indices for cells other than basal cells are very low $(<1 \%)$ in adult airway epithelia (37). While these data suggest

\section{Figure 3}

Gene transfer to rabbit tracheal epithelia in vivo using FIV- $\beta$ gal vector. Panels show results 5 days after gene transfer. Low magnification en face view of X-gal-stained trachea from control (a) or FIV vector-treated trachea (b). Blue cells were only seen in the trachea transduced with the FIV vector (b). (c) Low-magnification view of $X$-gal-stained tracheal section. $\beta$-galactosidase-expressing cells are noted at both the surface and basal cell levels of the transduced epithelium. (d-f) Higher-magnification views of tracheal epithelium showing cell types expressing $\beta$-galactosidase. No inflammatory cells were noted in control or transduced specimens ( $n=4$ animals). Scale bar in $\mathbf{d}$ also applies to $\mathbf{e}$ and $\mathbf{f}$.

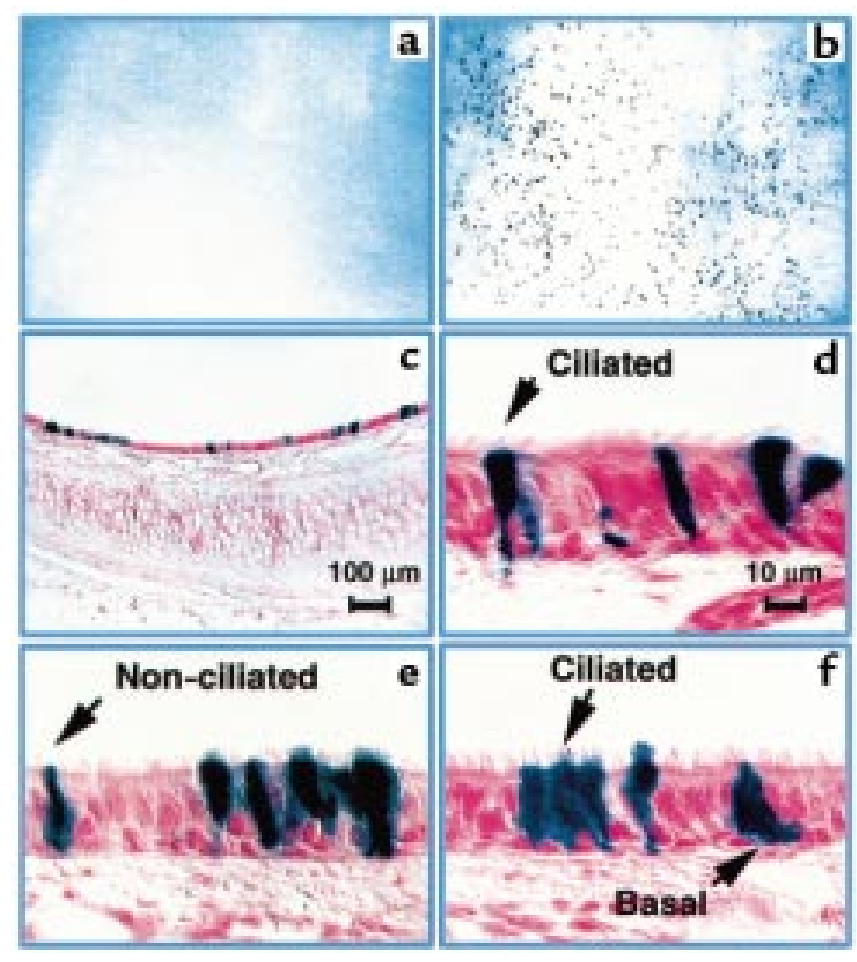



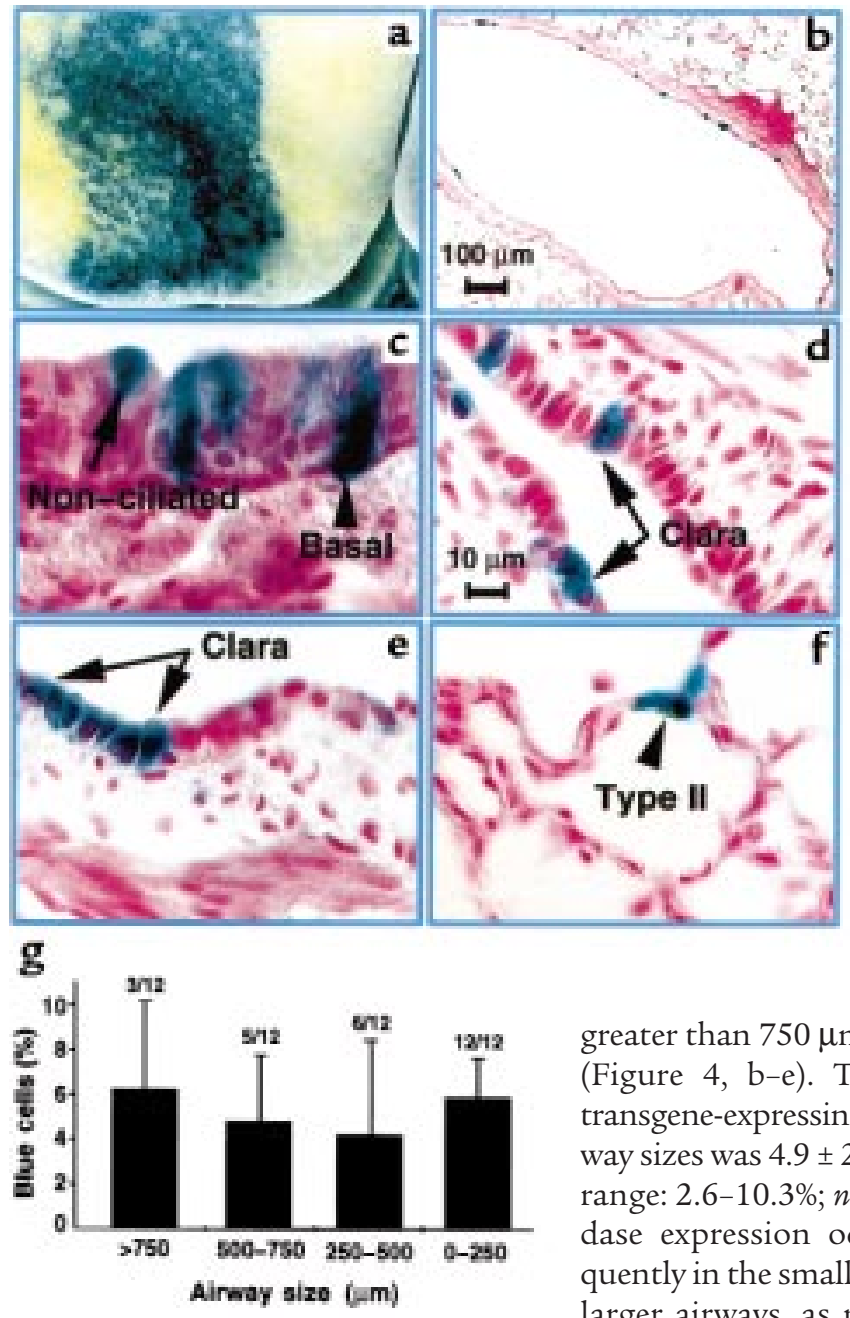

that FIV vectors transduce both dividing and nondividing airway cells in vivo, we cannot rule out the possibility that EGTA/hypotonic treatment stimulated some stationary-phase cells to divide. In the absence of EGTA formulation, there was no gene transfer (data not shown).

CF lung disease begins in the small airways. To target the intrapulmonary airways, a small catheter was passed transtracheally into the peripheral airways, and hypotonic/EGTA formulated FIV- $\beta$ gal vector was instilled. This approach allowed the vector solution to be concentrated within a relatively small area. As shown in Figure 4, a-e, we uniformly noted focal areas of gene transfer in the lung 5 days later. When serial sections of tissue were studied, epithelia expressing $\beta$ galactosidase were noted throughout the segment where virus was instilled, from cartilaginous bronchi with diameters

\section{Figure 4}

FIV- $\beta$ gal transduction of lower airway epithelia 5 days after gene transfer. (a) En face view of pleural surface of lung after fixation and X-gal staining showing $\beta$ galactosidase-expressing cells. All treated animals had similar segments of $\beta$-galactosidase-expressing cells extending to the pleural surface. (b-f) Higher magnification views of tissue sections showing lower airway and parenchymal cells transduced. (b) Low-magnification view of a large bronchus ( $>750 \mu \mathrm{m}$ diameter) demonstrating patches of $\beta$-galactosidase-expressing cells extending around the circumference of the epithelium. (c) High-magnification view of expression in a large bronchus (>750 $\mu \mathrm{m}$ diameter) showing expression in ciliated cells and basal cells. (d) High-magnification view of expression in a medium sized airway (500-750 $\mu \mathrm{m}$ diameter) demonstrating expression in nonciliated surface cells (Clara cells). (e) $\beta$-galactosidase expression in a small bronchus (250-500 $\mu \mathrm{m}$ diameter) showing expression in nonciliated surface cells (Clara cells). (f) Distal lung sample (airways 0-250 $\mu \mathrm{m}$ diameter) showing expression in cuboidal cells consistent with alveolar type II cells. (g) Gene transfer expressed as a function of airway size. Numbers above each bar represent the number of animals with transduced cells in the corresponding region. Tissues from 12 animals were studied. Scale bar in $\mathbf{d}$ also applies to $\mathbf{e}$ and $\mathbf{f}$. greater than $750 \mu \mathrm{m}$ out to the alveoli (Figure 4, b-e). The percentage of transgene-expressing cells across all airway sizes was $4.9 \pm 2.2 \%$ (mean $\pm \mathrm{SEM}$; range: $2.6-10.3 \% ; n=12$ ). $\beta$-galactosidase expression occurred more frequently in the smaller airways than the larger airways, as might be expected with the method of vector introduction (Figure 4g). Importantly, the morphology of the transduced airway epithelia appeared normal, and all cell types of the lower airways were transduced, including proposed progenitors such as basal cells, nonciliated surface cells (Clara cells), and alveolar type II cells. Vector instillation without the EGTA formulation resulted in no significant gene transfer (not shown).

FIV gene transfer to airway epithelia persists in vivo. Animals treated with FIV$\beta$ gal vector intratracheally were evaluated 6 weeks after gene transfer for persistence of gene expression. In contrast to the results at day 5 (Figure 3 , $a-e)$, larger clusters of $\beta$-galactosidase-positive cells were noted on both the en face views and the cross sections of the trachea (Figure 5), suggesting that targeted cells clonally expanded over time. As shown in Figure 5, we noted $\beta$-galactosidase-expressing cells throughout the epithelium. The percentage of $\beta$-galactosidase-expressing cells was $2.5 \pm 2 \%$ (mean \pm SEM; range: $0.4-5.4 \% ; n=4)$. When compared with the level of expression at 5 days (Figure $3)$, this change was not significant $(P=$ 0.5 by $t$ test). Transduced cell types included basal cells, nonciliated surface cells, ciliated surface cells, cells containing mucus granules, intermediate cells, and rarely, epithelia of submucosal glands. As noted at the 5-day time point, the epithelial morphology appeared normal.

\section{Discussion}

For CF lung disease to be treated by gene therapy, there must be lasting correction of defective $\mathrm{Cl}^{-}$transport. In these studies, we make significant progress in addressing several fundamental limitations for gene transfer to airway epithelia. A shortcoming of most current vectors is their inability to effectively transduce airway epithelia when applied to the apical surface. The native receptors for many recombinant viruses are distributed on the basolateral cell surface of polarized cells. Previous investigators noted that VSV-G pseudotyped HIV lentivirus (13) and MuLV (10) inefficiently transduced differentiated airway epithelia in vivo. We $(9,11)$ and others $(38)$ reported this limitation with MuLV retrovirus envelopes, and there is 


\section{Figure 5}

$\beta$-galactosidase expression persists in vivo 6 weeks after gene transfer. (a) En face view demonstrating $\beta$-galactosidase-positive cells in the trachea. Larger clusters of blue cells (arrows) were noted at 6 weeks than at the earlier time point, suggesting clonal expansion of transduced cells. (b-d) Cross sections of tissue shown in a. Multiples cell types were targeted as indicated by the arrows. Clusters of $\beta$-galactosidase-positive cells were noted, suggesting clonal expansion of targeted cells ( $n=4$ animals). Epithelial morphology appeared normal as determined by examination of hematoxylin and eosin stained sections. Scale bar in $\mathbf{d}$ also applies to $\mathbf{b}$ and $\mathbf{c}$. SMG = submucosal gland
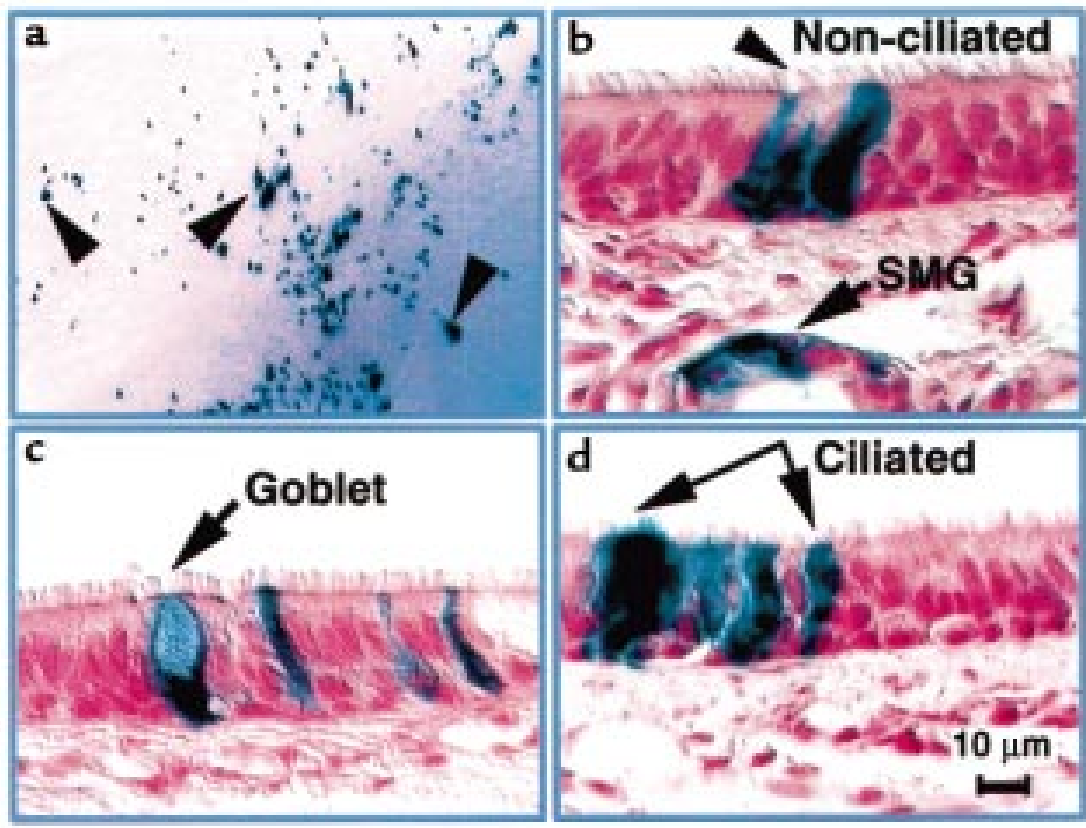

precedence for such a polarity of gene transfer to airway epithelia with other delivery systems including AAV (28, $39)$ and adenovirus vectors $(20,40)$ as well as cationic lipids (41). Although VSV-G-pseudotyped FIV transduced cells poorly from the apical surface, this limitation was overcome using hypotonic/EGTA vector formulation to transiently open epithelial junctions (42-44). Under these conditions, cells throughout the epithelium were transduced in vitro and in vivo, and the $\mathrm{CFTR}^{-} \mathrm{Cl}^{-}$transport defect was corrected in vitro.

The transduction efficiency of FIV vectors formulated with EGTA is within the range of $6-10 \%$ believed sufficient to correct the CF defect (45). Although this work focused on a single vector dose administration, it is possible that lentiviral vectors may be readministered with minimal immune responses and further increase the number of permanently corrected cells (46). This vector formulation method represents a technical advance for vector administration to polarized epithelia in vivo. To translate such a result to patients, epithelial junctions in the human lung could be transiently opened pharmacologically to facilitate vector access to receptors. Aerosol studies in humans show that it is technically feasible to transiently expose the airway epithelium to hypotonic conditions $\left(\mathrm{H}_{2} \mathrm{O}\right.$ aerosol) (47) or calcium chelators (EDTA aerosol) (48). In addition, pulmonary lavage under anesthesia might be developed to deliver vector solutions to the human airways. Such whole lung lavage procedures are currently used clinically to treat patients with alveolar proteinosis (49). With current integrating vectors, a lavage approach may be required to facilitate access to receptors on airway progenitor cells, as some of these cell types reside below the mucosal surface (e.g., basal cells, intermediate cells) (50-54).

A further encouraging result of this work was the normal morphology of the airway tissues after gene transfer. There was no evidence of cellular infiltration with immune effector cells when the rabbit airways were examined at the level of light microscopy (Figures 3, 4, and 5). Although this does not eliminate the possibility of any immune response, it contrasts with the cellular responses noted with adenoviral vectors $(24,55-57)$. Studies with HIV-based lentiviral vectors to date show no evidence of cellular immune responses at the sites of administration in vivo (46). Furthermore, HIV-based vectors (46) and MuLV vectors (58) can be administered a second time in vivo, suggesting that humoral immune responses may not prevent repeated dosing. Thus, enveloped viruses such as lentivirus or MuLV may be less immunogenic when delivered to the lung.

FIV vectors corrected the CFTR defect in vitro for the life of the culture. The failure of adenoviral-mediated CFTR correction to persist reflects both the lack of integration and the gradual loss and dilution of expressing cells by cell division. The persistence of CFTR correction in the FIV vectortransduced cells indicates successful targeting of cells with progenitor capacity. FIV-transduced epithelia also persisted in the trachea in vivo. There are several possible explanations for the small decline in gene expression we noted in the trachea between 5 days and 6 weeks. These include immune responses to the transgene, transcriptional shut off of the CMV promoter, loss of terminally differentiated cells that are targeted (i.e., ciliated cells), and variability related to the effective moi achieved in each animal. Future studies will evaluate these possibilities.

To our knowledge, this is the first evidence of in vivo transduction of airway epithelia with a lentiviral vector. As reported with HIV-based lentiviral vectors $(12,13,46)$ or equine infectious anemia virus (EIAV) vectors (59), the present studies show that recombinant FIV vectors transduce nondividing cells in vitro. This is an important finding, as the majority of airway 
epithelia are mitotically quiescent in the postnatal airways (60-62). FIV vectors transduced epithelial cells throughout the adult rabbit airways in vivo, and gene expression persisted for 6 weeks. Further studies are needed to document the proliferation status of cells at the time of transduction in vivo. Cell types believed to have progenitor capacity in the airway epithelium such as basal cells, intermediate cells, and nonciliated surface cells were transduced (50-52, 54). Integration of the proviral DNA into the host cell chromosome should allow the persistent expression of a therapeutic gene such as CFTR. These studies provide a strong rationale for a vector delivery approach that may be used for the treatment of genetic lung diseases.

\section{Acknowledgments}

We thank Phil Karp, Pary Weber, and Jan Launsbach for culturing the human epithelial cells; and Camille Deering, Royce Burns, Jeffrey Brannen, Kerry Wiles, and David Lewis for technical assistance. We thank Hoger Roehl for the development of the PCR titer assay, and Philip Sheridan for the determination of titers by PCR. We thank Michael Welsh, Stanley Perlman, and John Engelhardt for helpful discussions. This work was funded by the Cystic Fibrosis Foundation PO96 (P.B. McCray and B.L. Davidson), National Institute of Health (NIH) RO1HL61460 (P.B. McCray and B.L. Davidson), NIH PPG HL-51670 (P.B. McCray and B.L. Davidson), and the Children's Miracle Network Telethon. We acknowledge the support of the Morphology Core, the Vector Core and Cell Culture Core, partially supported by the Cystic Fibrosis Foundation, NHLBI (PPG HL51670-05), the Carver Foundation, and the Center for Gene Therapy for Cystic Fibrosis (NIH P30 DK-97-010). P.B. McCray is a recipient of a Career Investigator Award from the American Lung Association. B.L. Davidson and J. Zabner are Fellows of the Roy J. Carver Charitable Trust.

1. Welsh, M.J., Boat, T.F., Tsui, L.-C., and Beaudet, A.L. 1995. Cystic fibrosis. In The metabolic and molecular basis of inherited disease. C.R. Scriver, A.L. Beaudet, W.S. Sly, and D. Valle, editors. McGraw-Hill Inc. New York, NY. 3799-3876.

2. Ramsey, B.W. 1996. Drug therapy: management of pulmonary disease in patients with cystic fibrosis [review]. N. Engl. J. Med. 335:179-188.

3. Rich, D.P., et al. 1990. Expression of cystic fibrosis transmembrane conductance regulator corrects defective chloride channel regulation in cystic fibrosis airway epithelial cells. Nature 347:358-363.

4. Drumm, M.L., et al. 1990. Correction of the cystic fibrosis defect in vitro by retrovirus-mediated gene transfer. Cell. 62:1227-1233.

5. Miao, C.H., et al. 1998. The kinetics of rAAV integration in the liver. Nat. Genet. 19:13-15.

6. Nakai, H., Iwaki, Y., Kay, M.A., and Couto, L.B. 1999. Isolation of recombinant adeno-associated virus vector-cellular DNA junctions from mouse liver. J. Virol. 73:5438-5447.

7. Olsen, J.C., et al. 1992. Correction of the apical membrane chloride permeability defect in polarized cystic fibrosis airway epithelia following retroviral-mediated gene transfer. Hum. Gene Ther. 3:253-266.

8. Halbert, C.L., Aitken, M.L., and Miller, A.D. 1996. Retroviral vectors efficiently transduce basal and secretory airway epithelial cells in vitro resulting in persistent gene expression in organotypic culture. Hum. Gene Ther. 7:1871-1881.

9. Wang, G., et al. 1998. Influence of cell polarity on retrovirus-mediated gene transfer to differentiated human airway epithelia. J. Virol. 72:9818-9826.

10. Johnson, L.G., et al. 1998. Effect of host modification and age on airway epithelial gene transfer mediated by a murine leukemia virus-derived vector. J. Virol. 72:8861-8872.

11. Wang, G., et al. 1999. Keratinocyte growth factor induced epithelial proliferation facilitates retroviral-mediated gene transfer to pulmonary epithelia in vivo. J. Gene. Med. 1:22-30.

12. Naldini, L., et al. 1996. In vivo gene delivery and stable transduction of nondividing cells by a lentiviral vector. Science. 272:263-267.

13. Goldman, M.J., Lee, P.-S., Yang, J.-S., and Wilson, J.M. 1997. Lentiviral vectors for gene therapy of cystic fibrosis. Hum. Gene Ther. 8:2261-2268.

14. Poeschla, E.M., Staal, F.W., and Looney, D.L. 1998. Efficient transduction of nondividing human cells by feline immunodeficiency virus lentiviral vectors. Nat. Med. 4:354-357.

15. Johnston, J.C., et al. 1999. Minimum requirements for efficient transduction of dividing and nondividing cells by feline immunodeficiency virus vectors. J. Virol. 73:4991-5000.

16. Hartmann, K. 1998. Feline immunodeficiency virus infection: an overview [review]. Vet. J. 155:123-137.

17. Zabner, J., Zeiher, B.G., Friedman, E., and Welsh, M.J. 1996. Adenovirus-mediated gene transfer to ciliated airway epithelia requires prolonged incubation time. J. Virol. 70:6994-7003.

18. Yamaya, M., Finkbeiner, W.E., Chun, S.Y., and Widdicombe, J.H. 1992. Differentiated structure and function of cultures from human tracheal epithelium. Am. J. Physiol. 262:L713-L724.

19. Rommens, J.M., et al. 1989. Identification of the cystic fibrosis gene: chromosome walking and jumping. Science. 245:1059-1065.

20. Walters, R.W., et al. 1999. Basolateral localization of fiber receptors limits adenovirus infection of airway epithelia. J. Biol. Chem. 274:10219-10226.

21. Scaria, A., et al. 1998. Adenovirus-mediated persistent cystic fibrosis transmembrane conductance regulator expression in mouse airway epithelium. J. Virol. 72:7302-7309.

22. Liu, M.-L., Winther, B.L., and Kay, M.A. 1996. Pseudotransduction of hepatocytes by using concentrated pseudotyped vesicular stomatitis virus G glycoprotein (VSV-G)-moloney murine leukemia virus-derived retrovirus vectors: comparison of VSV-G and amphotropic vectors for hepatic gene transfer. J. Virol. 70:2497-2502

23. Alexander, I.E., Russell, D.W., and Miller, A.D. 1997. Transfer of contaminants in adeno-associated virus vector stocks can mimic transduction and lead to artifactual results. Hum. Gene Ther.
8:1911-1920.

24. McCray, P.B., Jr., et al. 1995. Adenoviral-mediated gene transfer to fetal pulmonary epithelia in vitro and in vivo. J. Clin. Invest. 95:2620-2632.

25. Fuller, S., von Bonsdorff, C.H., and Simons, K. 1984. Vesicular stomatitis virus infects and matures only through the basolateral surface of the polarized epithelial cell line, MDCK. Cell. 38:65-77.

26. Thomas, D.C., and Roth, M.G. 1994. The basolateral targeting signal in the cytoplasmic domain of glycoprotein $\mathrm{G}$ from vesicular stomatitis virus resembles a variety of intracellular targeting motifs related by primary sequence but having diverse targeting activities. J. Biol. Chem. 269:15732-15739.

27.Zabner, J., Fasbender, A.J., Moninger, T. Poellinger, K.A., and Welsh, M.J. 1995. Cellular and molecular barriers to gene transfer by a cationic lipid. J. Biol. Chem. 270:18997-19007.

28. Duan, D., Yue, Y., McCray, P.B., Jr., and Engelhardt, J.F. 1998. Polarity influences the efficiency of recombinant adeno-associated virus infection in differentiated airway epithelia. Hum. Gene Ther 9:2761-2776.

29. Zabner, J., Smith, J.J., Karp, P.H., Widdicombe, J.H., and Welsh, M.J. 1998. Loss of CFTR chloride channels alters salt absorption by cystic fibrosis airway epithelia in vitro. Mol. Cell. 2:397-403.

30. McCray, P.B., Jr., Zabner, J., Jia, H.P., Welsh, M.J., and Thorne, P.S. 1999. Efficient killing of inhaled bacteria in $\triangle F 508$ mice: role of airway surface liquid composition. Am. J. Physiol. 277:L183-L190.

31. Zeiher, B.G., et al. 1995. A mouse model for the $\Delta$ F508 allele of cystic fibrosis. J. Clin. Invest. 96:2051-2064.

32. O'Neal, W.K., et al. 1993. A severe phenotype in mice with a duplication of exon 3 in the cystic fibrosis locus. Hum. Mol. Genet. 2:1561-1569.

33. Colledge, W.H., et al. 1995. Generation and characterization of a $\Delta \mathrm{F} 508$ cystic fibrosis mouse model. Nat. Genet. 10:445-452.

34. Kent, G., et al. 1996. Phenotypic abnormalities in long-term surviving cystic fibrosis mice. Pediatr. Res. 40:233-241.

35. Snouwaert, J.N., et al. 1995. A murine model of cystic fibrosis. Am. J. Respir. Crit. Care Med. 151:S59-S64.

36. Smith, J.J., Travis, S.M., Greenberg, E.P., and Welsh, M.J. 1996. Cystic fibrosis airway epithelia fail to kill bacteria because of abnormal airway surface fluid. Cell. 85:229-236.

37. Shami, S.G., and Evans, M.J. 1991. Kinetics of pulmonary cells. In Comparative biology of the normal lung. R.A. Parent, editor. CRC Press. Boca Raton, FL. 145-155.

38. Zsengeller, Z.K., et al. 1999. Keratinocyte growth factor stimulates transduction of the respiratory epithelium by retroviral vectors. Hum. Gene Ther 10:341-353.

39. Teramoto, S., et al. 1998. Factors influencing adeno-associated virus-mediated gene transfer to human cystic fibrosis airway epithelial cells: comparison with adenovirus vectors. J. Virol. 72:8904-8912.

40. Pickles, R.J., et al. 1998. Limited entry of adenovirus vectors into well-differentiated airway epithelium is responsible for inefficient gene transfer. J. Virol. 72:6014-6023.

41. Chu, Q., et al. 1999. Binding and uptake of cationic lipid: pDNA complexes by polarized airway epithelial cells. Hum. Gene Ther. 10:25-36.

42. Widdicombe, J.H., Azizi, F., Kang, T., and Pittet, J.F. 1996. Transient permeabilization of airway epithelium by mucosal water. J. Appl. Physiol. 81:491-499.

43. Anderson, J.M., and Itallie, C.M. 1995. Tight junctions and the molecular basis for regulation of paracellular permeability. Am. J. Physiol. 269:G467-G475.

44. Denker, B.M., and Nigam, S.K. 1998. Molecular structure and assembly of the tight junction [review]. Am. J. Physiol. 274:F1-F9. 
45. Johnson, L.G., et al. 1992. Efficiency of gene transfer for restoration of normal airway epithelial function in cystic fibrosis. Nat. Genet. 2:21-25.

46. Kafri, T., Blomer, U., Peterson, D.A., Gage, F.H., and Verma, I.M. 1997. Sustained expression of genes delivered directly into liver and muscle by lentiviral vectors. Nat. Genet. 17:314-317.

47. Chan, H.-K., et al. 1994. Regional deposition of nebulized hypodense nonisotonic solutions in the human respiratory tract. Eur. Respir. J. 7:1483-1489.

48. Brown, J., Mellis, C.M., and Wood, R.E. 1985. Edetate sodium aerosol in psendomonas lung infection in cystic fibrosis. Am. J. Dis. Child. 139:836-839.

49. Rodi, G., et al 1995. Whole lung lavage. Monaldi Arch. Chest Dis. 50:64-66.

50. Plopper, C.G., Nishio, S.J., Kass, A.P., and Hyde, D.M. 1992. The role of the nonciliated bronchiolar epithelial (Clara) cell as the progenitor cell during bronchiolar epithelial differentiation in the perinatal rabbit lung. Am. J. Respir. Cell Mol.
Biol. 7:606-613.

51. Johnson, N.F., and Hubbs, A.F. 1990. Epithelial progenitor cells in the rat trachea. Am. J. Respir. Cell Mol. Biol. 3:579-585.

52. Inayama, Y., et al. 1988. The differentiation potential of tracheal basal cells. Lab. Invest. 58:706-717.

53. Randell, S.H. 1992. Progenitor-progeny relationships in airway epithelium. Chest. 101(Suppl.):11S-16S.

54. Evans, M.J., Johnson, L.V., Stephens, R.J., and Freeman, G. 1976. Renewal of the terminal bronchiolar epithelium in the rat following exposure to $\mathrm{NO}_{2}$ or $\mathrm{O}_{3}$. Lab. Invest. 35:246-257.

55. Simon, R.H., et al. 1993. Adenovirus-mediated transfer of the CFTR gene to lung of nonhuman primates: toxicity study. Hum. Gene Ther. 4:771-780.

56. Zsengeller, Z.K., et al. 1995. Persistence of replication-deficient adenovirus-mediated gene transfer in lungs of immune-deficient (nu/nu) mice. Hum. Gene Ther. 6:457-467.

57. Kaplan, J.M., et al. 1996. Humoral and cellular immune responses of nonhuman primates to long-term repeated lung exposure to Ad2/CFTR2. Gene Ther. 3:117-127.

58. McCormack, J.E., et al. 1997. Anti-vector immunoglobulin induced by retroviral vectors. Hum. Gene Ther. 8:1263-1273.

59. Olsen, J.C. 1998. Gene transfer vectors derived from equine infectious anemia virus. Gene Ther. 5:1481-1487.

60. McCray, P.B., Jr., Wang, G., O’Brien, L., Davidson, B.L., and Thomas, P. 1997. Proliferation indices of pulmonary epithelia during human and ovine lung development: gene transfer targets for integrating vectors. Cell Vision. 4:1-8.

61. Ayers, M.M., and Jeffery, P.K. 1988. Proliferation and differentiation in mammalian airway epithelium. Eur. Respir. J. 1:58-80.

62. Leigh, M.W., Kylander, J.E., Yankaskas, J.R., and Boucher, R.C. 1995. Cell proliferation in bronchial epithelium and submucosal glands of cystic fibrosis patients. Am. J. Respir. Cell Mol. Biol. 12:605-612 